\title{
Gellan Gum-Based Bilayer Mucoadhesive Films Loaded with Moxifloxacin Hydrochloride and Clove Oil for Possible Treatment of Periodontitis
}

\author{
Aiqin $\mathrm{Li}^{1}$ \\ Ifrah Nabi Khan ${ }^{2}$ \\ Ikram Ullah Khan ${ }^{2}$ \\ Abid Mehmood Yousaf $\mathbb{D D}^{3}$ \\ Yasser Shahzad (iD ${ }^{3}$ \\ 'Department of Stomatology, Zhengzhou \\ Central Hospital Affiliated to Zhengzhou \\ University, Zhengzhou, People's Republic \\ of China; ${ }^{2}$ Department of Pharmaceutics, \\ Faculty of Pharmaceutical Sciences, \\ Government College University \\ Faisalabad, Faisalabad, Pakistan; \\ ${ }^{3}$ Department of Pharmacy, COMSATS \\ University Islamabad, Lahore, Pakistan
}

Correspondence: Yasser Shahzad Department of Pharmacy, COMSATS University Islamabad, Lahore Campus, Lahore, Pakistan

Email y.shahzad@live.com

Ikram Ullah Khan

Department of Pharmaceutics, Faculty of Pharmaceutical Sciences, Government College University Faisalabad, Faisalabad, Pakistan

Email ikramglt@gmail.com
Background/Objective: Periodontitis is a widely spread oral infection and various antibiotics are utilized for its treatment, but high oral doses and development of antibiotic resistance limit their use. This study was aimed at development of natural polymer-based mucoadhesive bilayer films loaded with moxifloxacin hydrochloride (Mox) and clove essential oil (CEO) to potentially combat bacterial infection associated with periodontitis.

Methods: Films were synthesized by double solvent casting technique having an antibiotic in the gellan gum-based primary layer with clove oil in a hydroxyethyl cellulose-based secondary layer.

Results: Prepared films were transparent, flexible, and showed high antibacterial response against both gram-positive and gram-negative bacteria. The films showed excellent pharmaceutical attributes in terms of drug content, folding endurance, swelling index, and mucoadhesive strength. Solid state characterization of formulation showed successful incorporation of drug and oil in separate layers of hydrogel structure. An in-vitro release study showed an initial burst release of drug followed by sustained release for up to 48 hours.

Conclusion: The prepared mucoadhesive bilayer buccal films could be used as a potential therapeutic option for the management of periodontitis.

Keywords: gellan gum, hydroxyethyl cellulose, bilayer films, mucoadhesive, moxifloxacin hydrochloride, clove oil

\section{Introduction}

Periodontitis is a globally widespread bacterial infectious disease which is characterized by the damage of the periodontal tissues followed by the loss in periodontal ligament and alveolar bone. ${ }^{1}$ Periodontal disease is considered as the major cause of tooth loss and other oral problems, and it is also associated with other diseases such as diabetes mellitus, atherosclerotic vascular disease, infective endocarditis, and chronic nephritis. ${ }^{2}$ The most prominent causative microorganisms are Porphyromonas gingivalis, Prevotella intermedia, Tannerella forsythia, Aggregatibacter actinomycetemcomitans, Fusobacterium nucleatum, and many others. $^{3}$ It has recently been established that Gram-negative and Gram-positive bacteria are associated with the progression of periodontal bone loss. ${ }^{4}$ For the treatment of periodontal disease, various strategies have been developed including conventional procedures, scaling, and root planning; however these procedures are highly dependent upon clinician's skill and have an inability to reach into deep pockets or furcation areas. ${ }^{5}$ Similarly in systemic antimicrobial therapy, 
maintenance of effective concentration at the required site is difficult and long-term therapy often leads to microbial resistance. ${ }^{6}$ These shortcomings can be overcome by advanced drug loaded biomaterials such as micro/nanofibers, membranes, hydrogels, or nanoparticles that not only provide precise and controlled drug release but also target the microbes invading intra-periodontal pockets. ${ }^{7}$ Among these biomaterials, hydrogel film incorporated with an antimicrobial agent is a promising approach to treat periodontitis due to its mucoadhesivity, biodegradability, biocompatibility, non-toxicity, controllability of drug release, and can be easily inserted into target place. ${ }^{2,8}$

Bilayer films are the drug delivery system that contains more than one active pharmaceutical agent in a double layered polymeric film. ${ }^{9}$ Recently, bilayer films are gaining preference over single layer films as they offer a combination of unique properties of all substrates, which is often advantageous. ${ }^{10}$ Bilayer films can be made as mucoadhesive films by using mucoadhesive polymers with the added advantage of incorporating a sustained drug release layer ${ }^{11}$ and an immediate drug release. $^{12}$ Various mucoadhesive films containing antimicrobial agents for the treatment of periodontitis have been reported; $;^{3,13-15}$ however, no significant efforts have been made in designing bi-layered mucoadhesive films for potential periodontitis treatment.

Several natural or synthetic polymers have been used to formulate hydrogel films; however, natural polymers are preferred over synthetic polymer due to their biocompatibility and biodegradability. Gellan gum is a natural anionic polymer obtained from the bacteria, Pseudomonas elodea, ${ }^{16}$ and is widely utilized in pharmaceutical formulations as gelling and/or mucoadhesive agent because of its non-toxicity, biocompatibility, and biodegradability. Gellan gum based membranes have also been used for repairing different organs and tissues. ${ }^{17}$

Hydroxyethyl cellulose (HEC) is a polysaccharide derivative and a biomaterial with excellent properties of biocompatibility, oxygen and nutrients permeability, and high porosity. HEC is a water-soluble polymer that is used as a binder, lubricant, emulsifying, thickening, and stabilizing agent in pharmaceutical formulations. ${ }^{18}$

Mox is a fourth-generation fluoroquinolones with broad anti-bacterial activity. It interferes with the binding of bacterial enzyme DNA gyrase and topoisomerase IV ${ }^{19}$ and is indicated for moderate-to-severe oral infections. ${ }^{20}$ Similarly, use of essential oils has also been reported for the treatment of oral cavity infections due to their analgesic, antibacterial, antiviral, anti-inflammatory, and antioxidant activity, either alone or in combination with synthetic drugs to minimize the chances of drug resistance. $^{17,21}$ Various researchers have incorporated essential oils into mucoadhesive films or other delivery systems with great potential for the treatment of oral cavity infections. $^{22-24}$

Herein, we combined Mox and clove oil in mucoadhesive bilayer buccal films for potential application in periodontitis. It is anticipated that antibacterial drug will combat the oral bacterial infections while the clove oil will help in soothing the pain. The prepared bilayer films will be evaluated for various pharmaceutical quality attributes and their antibacterial activity will be assessed against gram-positive and gram-negative bacterial strains.

\section{Materials and Methods}

Gellan gum (GG) was sourced from Alfa Aesar (Thermo Fisher Scientific, Heysham, UK). Hydroxyethyl cellulose, calcium chloride, and propylene glycol was procured from Sigma Aldrich (St. Louis, MO). Tween 80 was obtained from Merck (Darmstadt, Germany). Moxifloxacin hydrochloride was received as a gift sample from Saffron Pharmaceutical Pvt. Ltd (Faisalabad, Pakistan) with a minimum purity of $99 \%$. Clove oil was acquired from Haque Planters International (Karachi, Pakistan). All the other chemicals and reagents used were of analytical grade. Deionized water prepared at an in-house facility was used throughout the experiment.

\section{Preparation of Bilayer Films}

The bilayer film formulation ingredients are presented in Table 1 and the preparation steps are depicted in Figure 1. The first layer was prepared by dissolving $0.1 \mathrm{~g}$ gellan gum in $7 \mathrm{~mL}$ of distilled water with constant stirring at $60-70^{\circ} \mathrm{C}$ for 1 hour. Meanwhile, propylene glycol $(15 \% \mathrm{w} / \mathrm{w}$ of polymer) was added into the solution with constant stirring. Later, the drug solution was prepared by dissolving $30 \mathrm{mg}$ of Mox in $3 \mathrm{~mL}$ of distilled water. Then drug solution was poured slowly into the polymeric solution with continuous stirring. After 1 hour, gellan gum and drug solution were casted in a glass petri plate. Freshly prepared $0.5 \% \mathrm{w} / \mathrm{v}$ calcium chloride solution was sprayed over the solution cast petri plate using a spray bottle. Then, the petri plate was placed on a flat surface to air dry the first layer.

A second polymeric layer containing oil was prepared by dissolving $0.1 \mathrm{~g}$ hydroxyethyl cellulose in $10 \mathrm{~mL}$ distilled water under constant stirring. Propylene glycol $(15 \% \mathrm{w} / \mathrm{w}$ of 
Table I Formulation of Drug and Oil Loaded Bilayer Films

\begin{tabular}{|l|l|l|l|l|l|}
\hline $\begin{array}{l}\text { S. } \\
\text { no }\end{array}$ & $\begin{array}{l}\text { Formulation } \\
\text { Code }\end{array}$ & $\begin{array}{l}\text { GG } \\
\text { (g) }\end{array}$ & $\begin{array}{l}\text { HEC } \\
\text { (g) }\end{array}$ & $\begin{array}{l}\text { Mox } \\
(\mathbf{m g})\end{array}$ & $\begin{array}{l}\text { CEO (\% } \\
\text { w/w) }\end{array}$ \\
\hline I & B & 0.1 & 0.1 & - & - \\
$\mathbf{2}$ & D & 0.1 & 0.1 & 30 & - \\
$\mathbf{3}$ & OI & 0.1 & 0.1 & - & 12.5 \\
$\mathbf{4}$ & O2 & 0.1 & 0.1 & - & 25 \\
$\mathbf{5}$ & O3 & 0.1 & 0.1 & - & 50 \\
$\mathbf{6}$ & GG I & 0.1 & 0.1 & 30 & 12.5 \\
$\mathbf{7}$ & GG2 & 0.1 & 0.1 & 30 & 25 \\
$\mathbf{8}$ & GG3 & 0.1 & 0.1 & 30 & 50 \\
\hline
\end{tabular}

Abbreviations: B, black; DI, drug loaded; (OI-O3), oil loaded; (GGI-GG3), both oil and drug loaded; GG, gellan gum; HEC, hydroxyethyl cellulose; Mox, moxifloxacin hydrochloride; CEO, clove essential oil.

polymer) was added into the polymeric solution. $0.2 \% \mathrm{w} / \mathrm{v}$ of tween 80 and varying concentration of clove oil (up to $50 \% \mathrm{w} / \mathrm{w}$ of polymer) was added in $3 \mathrm{~mL}$ of ethanol and stirred gently to mix them. Upon proper mixing of tween 80 and clove oil in ethanol, the solution was added dropwise into the polymeric solution of hydroxyethyl cellulose with continuous stirring. It should be noted that tween 80 was added in all oil-loaded formulations. Then, the solution was sonicated for 5 minutes to remove air bubbles and cast onto the previously dried first film layer and air dried. Resultant bilayer film was peeled off from the petri plate and subsequently cut into specified dimensions $\left(1.5 \times 1.5 \mathrm{~cm}^{2}\right)$, packed in aluminum foil and stored until further use.

\section{Antibacterial Activity}

The prepared films were evaluated for the anti-bacterial assay against the gram-positive and gram-negative bacterial strains, namely Staphylococcus aureus (ATCC 6538P) and Escherichia coli (ATCC 25922), respectively. For this purpose, the agar well diffusion method was used. The standardized inoculum was prepared by activating bacterial strains in tryptic soy agar (TSA) culture media for 24 hours and incubating at $37^{\circ} \mathrm{C}$ until it reached $1 \times 10^{9}$ colony forming unit per $\mathrm{mL}$. The surface of the nutrient agar plates was inoculated by dispersing the standardized inoculum of the test microorganisms over the whole

\section{Preparation of primary layer}
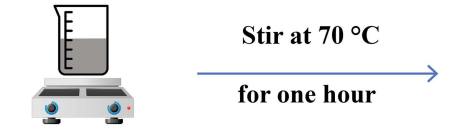

Gellan gum solution

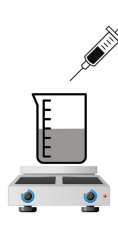

Addition of propylene glycol

\section{Preparation of secondary layer}

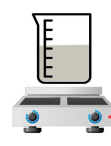

Hydroxyethyl cellulose solution
Stir at $500 \mathrm{rpm}$

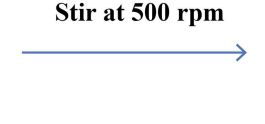

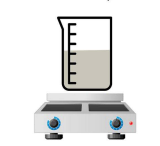

Addition of prolylene glycol

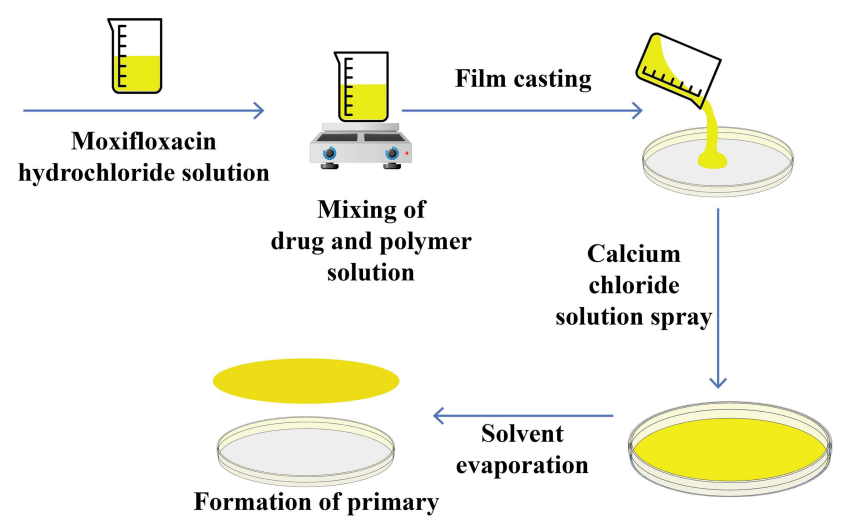

layer
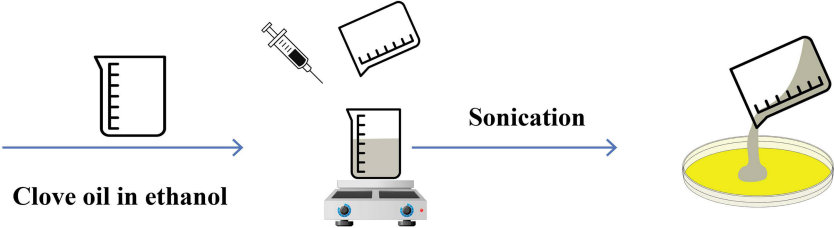

Film casting

Addition of tween 80 and clove oil solution in HEC solution

Bilayer film

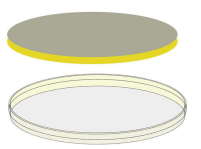

Drying and peeling

Figure I Flow diagram of synthesis of bilayer buccal films. 
surface. Then, a sterile cork borer was used to punch a 5$8 \mathrm{~mm}$ diameter hole. The mucoadhesive films, cut into discs, were placed in the center of the agar plate and a volume of $20-100 \mu \mathrm{L}$ of phosphate buffer saline $(\mathrm{pH}$ 6.8) was introduced into the well. Then, the agar plates were incubated under specific conditions. After the specified time period, the zone of inhibition was calculated for each film against the gram-positive and gram-negative bacteria. This assay was performed in a triplicate manner. The zone of inhibition was measured in $\mathrm{mm}^{25}$

\section{Weight Variation, Thickness, Disintegration Time, and Folding Endurance}

To calculate the variation in the weight of prepared films, the weight of the films was determined gravimetrically using the OHAUS $^{\mathrm{TM}}$ analytical weighing balance. The average weight was computed and the results are expressed as mean \pm standard deviation (SD) of five readings. The thickness of films at five different locations was measured by a Song Qi digital micrometer (model number: SQ-SXQFC031 with an accuracy of $0.02 \mathrm{~mm} / 0.001$ ") and an average value was calculated. For disintegration time evaluation, the film was cut into $1.5 \times 1.5 \mathrm{~cm}^{2}$ pieces and placed in a petri plate containing $10 \mathrm{~mL}$ distilled water. The total time taken by the film to disintegrate was noted using a digital stopwatch. ${ }^{26}$ The procedure was performed in triplicate.

A folding endurance test was performed to check the mechanical properties of formulated films. Briefly, a piece of film was folded repeatedly until cracks appeared or the film broke, and the corresponding number of folds were recorded to represent folding endurance. Generally, film that depicts a higher folding endurance value possesses more mechanical strength. ${ }^{27}$

\section{Drug Content Uniformity}

The entrapment efficiency (EE\%) of films was examined by placing films of specific area $\left(1.5 \times 1.5 \mathrm{~cm}^{2}\right)$ in $20 \mathrm{~mL}$ of phosphate buffer saline $(\mathrm{pH}$ 6.8) until completely dissolved. Then the solution was filtered, suitably diluted, and analyzed using a UV visible spectrophotometer at $291 \mathrm{~nm} .{ }^{28}$ The drug concentration was calculated using a previously constructed calibration plot based on a series of dilutions. The calibration plot was linear in the concentration range of $0.5-20 \mu \mathrm{g} / \mathrm{mL}\left(\mathrm{R}^{2}=0.999\right.$, slope $=0.0844$, and intercept $=0.0174)$. The test was performed in triplicate manner and the results are reported as mean $\pm \mathrm{SD} .^{29}$ The EE $\%$ was calculated using equation 1 :

$$
\begin{aligned}
& \text { Entrapment } \\
& \text { efficiency }(E E \%)
\end{aligned}=\frac{\text { Experimental drug amount }}{\text { Theoretical drug amount }} \times 100
$$

\section{Swelling Studies}

For swelling studies, each film $(1.5 \times 1.5 \mathrm{~cm})$ was weighed and then placed in phosphate buffer saline solution $(\mathrm{pH}$ 6.8). At predetermined time periods $(0.25,0.5,1,2,3,4,6$, 8,24 , and 48 hours), ${ }^{30}$ each film was removed from the phosphate buffer, blotted dry with tissue paper, and weighed again. The degree of swelling was calculated by using equation 2 :

$$
\text { Swelling ratio }(\%)=\frac{W_{t}-W_{0}}{W_{0}} \times 100
$$

where $W_{t}$ is the weight of a film at time $t$, and $W_{0}$ is the weight of the film at time $0 .{ }^{31}$ This test was performed in triplicate and results are reported as mean $\pm \mathrm{SD}$.

\section{Mucoadhesion Study}

The mucoadhesive strength was measured by using the modified physical balance method. ${ }^{32}$ The test was performed by placing a dialysis membrane attached to the opening of a glass vial which was filled with phosphate buffer saline solution ( $\mathrm{pH} 6.8$ ) at $37 \pm 1^{\circ} \mathrm{C}$. The glass vial was capped with a cork and placed in a beaker having buffer solution. On the lower side of the cork, films were attached. For preliminary hydration, the film surface was soaked with phosphate buffer and left for 15 seconds. Firstly, a preload weight of $20 \mathrm{~g}$ was placed over the other side of the pan. Respectively, at certain time intervals, weights were added onto the pan. The total weight (in grams) required to completely separate the films was termed the mucoadhesive strength. The following parameters were calculated from the mucoadhesive test study. ${ }^{33}$

$$
\begin{aligned}
& \begin{array}{l}
\begin{array}{l}
\text { Force of } \\
\text { adhesion }(N)
\end{array}=\frac{\text { Mucoadhesive strength }(g) \times 9.81}{1,000} \\
\text { Eq.3 } \\
\text { Bond strength }\left(\frac{N}{\mathrm{~m}^{2}}\right)=\frac{\text { Force of adhesion }}{\text { Film surface area }}
\end{array} \quad \text { Eq.4 }
\end{aligned}
$$

\section{Solid State Characterizations}

The surface morphology and cross-sectional views of the films were studied using scanning electron microscopy (SEM) (JEOL, JSM 5910, Japan). 
Possible drug and excipient interactions were studied using Fourier transform infrared spectroscopy (Thermo Scientific Nicolet iS5 ATR-FTIR, Waltham, MA) in the spectrum range of $500-4,000 \mathrm{~cm}^{-1}$ at a resolution of $2 \mathrm{~cm}^{-1}$.

Thermal stability of the drug was studied using simultaneous thermogravimetric analysis (TGA) and differential scanning calorimetry (TGA/DSC) (TA Instruments, SDT Q600 thermal analysis system, New Castle, DE). The thermal analysis was conducted by heating the sample in the temperature range of $25-400^{\circ} \mathrm{C}$ at an incremental heating rate of $10^{\circ} \mathrm{C} / \mathrm{min}$ under dry nitrogen purge flowing at $50 \mathrm{~mL} / \mathrm{h}$.

$\mathrm{X}$-ray diffraction (XRD) analysis of pure drug and film formulation was performed to evaluate the chemical structure, composition, and physical characteristics of the sample. The XRD spectra were acquired using X-ray diffractometer (X'pert PRO, Malvern PANalytical, Netherlands). The samples were placed in the sample holder and the diffractograms were obtained in the $2 \theta$ range of $5-80^{\circ}$.

\section{In-vitro Drug Release Studies}

The in-vitro drug release studies were performed using vertical Franz diffusion cells (Laboratory enterprises, India). Franz cells had effective permeation area of $1.76 \mathrm{~cm}^{2}$ with a receptor volume capacity of $9 \mathrm{~mL}$. Cellulose acetate membrane $(0.45 \mu \mathrm{m}$ pore size $)$ was cut into $25 \mathrm{~mm}$ discs and soaked in phosphate buffer saline (pH 6.8) solution for 30 minutes. The film was then placed on the receptor compartment in such a way that the mucoadhesive layer faced the receiver compartment. The film and membrane were mounted together, and all openings were sealed to avoid the evaporation of media. The experiment was performed at a temperature of $37 \pm 1^{\circ} \mathrm{C}$ and at a constant stirring rate of $500 \mathrm{rpm}$. Samples of $0.5 \mathrm{~mL}$ were withdrawn at time intervals of $0.5,1,2,3,4,5,6,7$, $8,10,12,24$, and 48 hours and replaced with an equal amount of freshly prepared pre-warmed buffer solution. The withdrawn samples were analyzed using a UV spectrophotometer at $291 \mathrm{~nm}$ after suitable dilution. The drug concentration was calculated based on the previously constructed calibration plot. The drug release experiment was performed in triplicate and mean $\pm \mathrm{SD}$ is reported.

\section{Release Kinetic Modeling}

Drug release data were fitted to various release kinetic models such as zero order, first order, Higuchi, and
Korsmeyer-Peppas model to evaluate the drug release mechanism. ${ }^{34}$ The dissolution of a drug from the modified release dosage form can be explained by zero-order kinetics:

$$
\mathrm{Q}_{\mathrm{t}}=\mathrm{Q}_{0}+\mathrm{K}_{0} \mathrm{t} \quad \text { Eq.5 }
$$

where $Q_{t}$ is the amount of drug dissolved in time $t, Q_{0}$ is the initial amount of drug in the solution, and $K_{0}$ is the zero order release constant stated in concentration/time units. $^{35}$

The first-order drug release can be explained by the following equation:

$$
\log \mathrm{Q}_{\mathrm{t}}=\log \mathrm{Q}_{0}-\mathrm{K}_{1 \mathrm{t}} \quad \text { Eq.6 }
$$

where $Q_{0}$ is the initial drug concentration, $Q_{t}$ is the drug concentration at time $t$, and $K$ is the first order rate constant. ${ }^{36}$

The drug release from a matrix system can be best explained by the Higuchi model, which is equated as follows:

$$
\mathrm{Q}_{\mathrm{t}}=\mathrm{K}_{\mathrm{H}} \times \mathrm{t}^{1 / 2}
$$

where $Q_{t}$ is the amount of drug at time $t$ and $K_{\mathrm{H}}$ is the Higuchi dissolution rate constant. ${ }^{37}$

Finally, the drug release mechanism can be explained on the basis of Korsmeyer-Peppas model, as presented by the following equation:

$$
\mathrm{M}_{\mathrm{t}} / \mathrm{M}_{\infty}=\mathrm{Kt}^{\mathrm{n}}
$$

where $M_{t} / M_{\infty}$ is the amount of drug release at time $t$ and at infinity, $K$ is the release rate constant, and $n$ is the release exponent. $^{34}$

\section{In vitro Permeation Studies}

Vertical Franz diffusion cells mounted with an established skin mimic, namely cellulose acetate membrane, were used for Mox permeation studies. The rest of the working conditions were the same as described in the drug release section. The cumulative amount of drug permeated per unit area was calculated using the following formula;

$$
Q t=\left(C t . V r+\sum C i V s\right) / A
$$

where $Q t$ represents the cumulative permeated amount of drug, $C t$ represents the drug concentration at each time interval, $V r$ represents the receptor volume, and $V s$ represents the receiving sample volume. $A$ denotes surface area.

Furthermore, steady-state flux $\left(J_{s s}\right)$ and permeability coefficient $(K p)$ were calculated according to the following equations; 


$$
\begin{gathered}
J_{s s}=\frac{\Delta Q t}{\Delta t \cdot A} \\
K_{p}=J_{s s} / C d
\end{gathered}
$$

where $C d$ represents the amount of drug in the donor compartment.

Lag time was calculated by extrapolating the linear portion of the cumulative amount of drug permeated per area versus time plot. $^{38}$

\section{Statistical Analysis}

All the data are reported as mean \pm standard deviation. Oneway ANOVA with Tukey's post-hoc analysis was applied to check the difference in mean values. A $P$-value less than 0.05 was considered as significant. The statistical analysis was performed on Origin software version 8.5 (OriginLab, Northampton, MA).

\section{Results and Discussion}

Here, we have demonstrated successful preparation of mucoadhesive bilayer films containing Mox and clove oil combination for potential use in periodontitis. This proofof-concept study was designed such that the immediate layer containing clove oil could provide an initial antiinflammatory and antibacterial effect, whilst a mucoadhesive gellan gum layer containing Mox provides a synergistic antibacterial effect in sustained manner. Clove essential oil comprises a mixture of 23 identified constituents, among them eugenol has the highest proportion $(76.8 \%)$, followed by $\beta$-caryophyllene $(17.4 \%), \alpha$ humulene $(2.1 \%)$, and eugenyl acetate $(1.2 \%)$ as the main components. ${ }^{39}$ Eugenol has many reported pharmacological applications, including analgesia, antibacterial, and antioxidant properties. ${ }^{40}$

In the quest of optimized formulation, various film combinations were evaluated for their antibacterial activity against gram-positive and gram-negative bacteria, and the data is presented in Table 2. Results revealed that the antibacterial activity of D1 was significantly $(P<0.05)$ higher than that for the blank film. When compared to antibacterial activity of clove oil-based films, we find an insignificant difference $(P>0.05)$ in the activity for $\mathrm{O} 1$ and $\mathrm{O} 2$ formulations with respect to the blank film (data not shown); however, O3 resulted in slightly higher antibacterial activity against both the gram-positive and gramnegative strains. Similarly, when lower concentrations of clove oil were combined with Mox (GG1 and GG2), no
Table 2 Zone of Inhibition of Prepared Formulations Against Selected Bacteria

\begin{tabular}{|l|l|l|}
\hline \multirow{2}{*}{ Formulation } & \multicolumn{2}{|c|}{ Zone of Inhibition (mm) } \\
\cline { 2 - 3 } & E. coli & S. aureus \\
\hline Blank & $14 \pm I$ & $I I \pm 2$ \\
DI & $48 \pm 3$ & $4 I \pm 3$ \\
O3 & $2 I \pm 4$ & $19 \pm I$ \\
GGI & $45 \pm I$ & $40 \pm 2$ \\
GG2 & $5 I \pm 3$ & $46 \pm I$ \\
GG3 & $67 \pm 2$ & $54 \pm 3$ \\
\hline
\end{tabular}

significant improvement $(P>005)$ in antibacterial activity was observed as compared with that obtained from the D1. However, a synergistic effect was observed when $50 \%$ clove oil was combined with Mox, which resulted in significantly higher $(P<0.05)$ antibacterial activity against both the bacterial strains. When comparing both strains, it was noted that bilayer films were more active against E. coli (gram-negative) as compared with S. aureus (grampositive). This is because Mox preferably targets the gyrase enzyme in gram-negative bacteria, whilst enzyme specificity is inverted in gram positive strains. ${ }^{41} \mathrm{~A}$ recent study suggested the use of polymeric nanofibers loaded with antibiotic combination for targeting gram-negative and gram-positive bacteria as a potential treatment strategy for periodontitis. ${ }^{42}$

Based on the antibacterial results, GG3 film was considered to be an optimized formulation for further testing. For the purpose of comparison, blank (B), D1, and O3 films were also subjected to various characterizations.

\section{Weight Variation, Thickness, Folding Endurance, and Disintegration Time}

A considerable variation in weight indicates method inefficiency and dose variation, ${ }^{43,44}$ thus it is necessary to evaluate these parameters. The average weight, thickness, and folding endurance of prepared bilayer films are presented in Table 3. The average weight of bilayer films ranged from $0.19-0.25 \mathrm{~g}$ with a very small variation in weight among each film system as witnessed by a relatively negligible standard deviation. The weight of films was well correlated with the thickness of the films, ie, with increasing weight of film, thickness also increased. Variation in thickness was also negligible, thus complementing the effective formulation procedure. Moreover, the thickness of bilayer films was well within the suitable range $(0.05-1.0 \mathrm{~mm})$, which is often required for the 
Table 3 Weight, Thickness, Folding Endurance and Disintegration Time (DT) of Films

\begin{tabular}{|l|c|c|c|c|c|}
\hline Formulations & $\begin{array}{c}\text { Weight Variation } \\
\mathbf{( g )}\end{array}$ & $\begin{array}{c}\text { Thickness } \\
\mathbf{( m m}\end{array}$ & $\begin{array}{c}\text { Folding } \\
\text { Endurance }\end{array}$ & $\begin{array}{c}\text { DT of Immediate Layer } \\
\mathbf{( m i n )}\end{array}$ & $\begin{array}{c}\text { DT of Sustained Layer } \\
\text { (Days) }\end{array}$ \\
\hline Blank & $0.19 \pm 0.01$ & $0.053 \pm 0.002$ & $209 \pm 12$ & $6 \pm 1.53$ & $18 \pm 1.00$ \\
D & $0.22 \pm 0.01$ & $0.054 \pm 0.002$ & $218 \pm 18$ & $10 \pm 0.57$ & $15 \pm 2.50$ \\
O3 & $0.24 \pm 0.03$ & $0.055 \pm 0.002$ & $213 \pm 16$ & $13 \pm 1.00$ & $20 \pm 1.52$ \\
GG3 & $0.25 \pm 0.03$ & $0.061 \pm 0.001$ & $227 \pm 14$ & $15 \pm 0.57$ & $25 \pm 2.00$ \\
\hline
\end{tabular}

mucoadhesive films. ${ }^{43}$ From a formulation point of view, consistency in weight and thickness among film strips from a single formulation ensures that the patient receives a constant dose every time.

The folding endurance is an indication of mechanical strength of a film. A film is considered mechanically strong if it withstands a higher number of folds without cracking or breaking. ${ }^{45}$ The folding endurance of our films ranged from 209-227 times, which endorsed the flexibility as well as mechanical strength of prepared films. The dsintegration time (DT) of films provides a clue about the bioavailability of drug in the body. Developed bilayer films were composed of two layers. The immediate layer was supposed to release the trapped constituent immediately, while the sustained layer had to release its ingredient in a controlled manner. The DT of both layers is given in Table 3, which shows that the immediate layer disintegrated quickly to provide rapid relief. On the other hand, the controlled layer required days to disintegrate, which assured the controlled release of Mox to provide an optimum therapeutic effect with minimum side-effects.

\section{Swelling Studies}

Swelling studies were carried out on bilayer films where the immediate layer contained clove oil and dissolved rapidly as compared to a crosslinked gellan gum layer containing Mox. The swelling index of films is depicted in Figure 2. All prepared films showed a good swelling index up to 8 hours, which was followed by a slight decrease in swelling index, possibly owing to polymeric erosion of both layers. ${ }^{17}$ For films an initial hydration and swelling are important functional characteristics that significantly affects mucoadhesion and drug release. ${ }^{45,46}$ The immediate layer dissolved quickly but the controlled layer swelled in three distinct steps. Firstly, adsorption of media on the surface of films due to the hydrophilic nature of gellan gum; secondly, swelling of crosslinked matrix due to carboxylic acid groups of gellan gum; and thirdly, surface saturation of water molecules drives liquid media into the film matrix. It leads to weakening of the intermolecular hydrogen bonding and expansion of the hydrogel matrix. ${ }^{17}$

During the first 15 hours of study, optimized film (GG3) exhibited a low swelling ratio as compared to the blank film. This is probably due to the limited aqueous solubility of clove oil (Eugenol: $2.46 \mathrm{mg} / \mathrm{mL}$ at $25^{\circ} \mathrm{C}$ ) and Mox $\left(24 \mathrm{mg} / \mathrm{mL}\right.$ at $\left.25^{\circ} \mathrm{C}\right)$ incorporated in immediate and controlled layers, respectively, which hindered the interaction of polymer with water medium. Similar results were reported by Hameed et al, ${ }^{47}$ who incorporated clove essential oil in nanofibers. After 15 hours, blank film resulted in slightly higher loss in swelling ratio as compared to GG3, which was attributed to superior interaction of blank film with water that resulted in polymer erosion. On the other hand, the D1 formulation showed slightly higher swelling as compared to $\mathrm{O} 3$, which was linked with presence of active ingredients with varying aqueous solubility, which defines the interaction of respective film with dissolution media. Similar results were obtained previously where gellan gum films had a higher swelling ratio initially and their swelling decreased after reaching saturation due to polymer erosion. ${ }^{17}$

\section{Fourier Transform Infrared Spectroscopy (FTIR)}

The FTIR spectra of pure drug (Mox), blank (B), oil loaded (O3), drug loaded (D1), and optimized formulation (GG3) was obtained to study the possible interaction between active ingredients and constituents of two layers of film (Figure 3). The spectra of pure drug showed characteristics peaks at $3,522 \mathrm{~cm}^{-1}$ due to stretching of hydroxyl group $(\mathrm{O}-\mathrm{H}), 3471 \mathrm{~cm}^{-1}$ represents the $-\mathrm{NH}$ stretching, $1,705 \mathrm{~cm}^{-1}$ denotes $\mathrm{C}=\mathrm{O}$ stretching, $1,621 \mathrm{~cm}$ ${ }^{-1}, 1,515 \mathrm{~cm}^{-1}$, and $1,454 \mathrm{~cm}^{-1}$ indicate aromatic $\mathrm{C}=\mathrm{C}$ stretching, $\mathrm{C}-\mathrm{N}$ stretching at $1,350 \mathrm{~cm}^{-1}$, monoflorobenzene stretching appears at $1,183 \mathrm{~cm}^{-1}$ and C-H bending at $873 \mathrm{~cm}^{-1}$ due to substituted benzene. ${ }^{48-50}$

The spectra of blank film showed peaks at $2,924 \mathrm{~cm}^{-1}$ and $2,917 \mathrm{~cm}^{-1}$ due to $\mathrm{C}-\mathrm{H}$ stretching of the $-\mathrm{CH}_{2}$ group, 


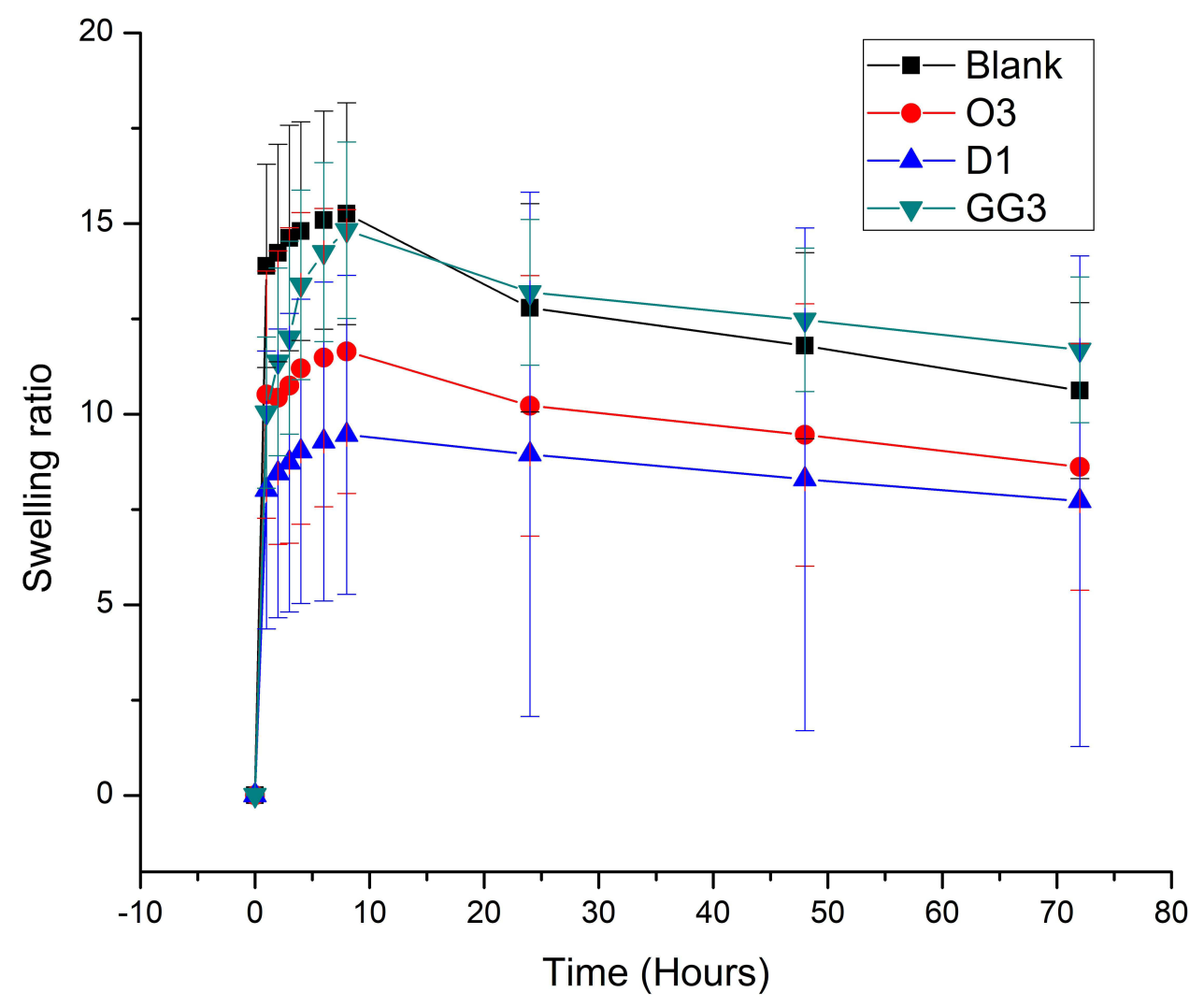

Figure 2 Swelling ratio of $\mathrm{B}, \mathrm{DI}, \mathrm{O} 3$, and GG3 formulation.

carbonyl group stretching occurs at $1,738 \mathrm{~cm}^{-1}, \mathrm{C}=\mathrm{C}$ stretching appears at $1,645 \mathrm{~cm}^{-1}$, glycosidic link stretching at about $1,611 \mathrm{~cm}^{-1}$, bands at $1,078 \mathrm{~cm}^{-1}$ and $1,037 \mathrm{~cm}^{-1}$ are due to primary alcoholic $-\mathrm{CH}_{2} \mathrm{OH}$ stretching and $\mathrm{CH}_{2}$ twisting vibrations, respectively, and $\mathrm{C}-\mathrm{H}$ bending vibrations appear at $835 \mathrm{~cm}^{-1} .51-53$

In O3 film, CEO characteristic peaks appear at 3,522 $\mathrm{cm}^{-1}$ due to hydroxyl group stretching of eugenol, C-O bending at $1,231 \mathrm{~cm}^{-1}, 1,010 \mathrm{~cm}^{-1}$ to $1,149 \mathrm{~cm}^{-1}$ ascribes to the etheric $\mathrm{C}-\mathrm{C}$ bond, and $\mathrm{C}-\mathrm{C}$ stretching in aromatic ring of essential oil at $1,609 \mathrm{~cm}^{-1}, 1,512 \mathrm{~cm}^{-1}$, and $1,430 \mathrm{~cm}^{-1} .54$

The spectra of drug-loaded film (D1) showed peaks corresponding to the pure drug $\left(3,471 \mathrm{~cm}^{-1}, 1,515 \mathrm{~cm}^{-1}\right.$, and $\left.1,705 \mathrm{~cm}^{-1}\right)$ and polymer $\left(2,917 \mathrm{~cm}^{-1}, 2,924 \mathrm{~cm}^{-1}\right.$, and $1,078 \mathrm{~cm}^{-1}$ ). This demonstrates successful incorporation of drug in the film without any interaction. ${ }^{55}$

After confirming the absence of interaction between only oil and drug containing bilayer films, we were interested to further evaluate how these two actives would behave when encapsulated in optimized formulation. FTIR spectra of GG3 does not reveal any new peaks. Thus, confirming the presence of CEO and Mox in the optimized film formulation without any pronounced interaction.

\section{Scanning Electron Microscopy (SEM)}

SEM is a widely employed technique to study the submicroscopic details of various carriers including bilayer films. SEM images of pure drug, blank, and GG3 films are shown in Figure 4. The surface view of Mox showed the crystalline nature of the drug (Figure 4A), which was further confirmed by XRD results. A cross-section of blank films shows two distinct layers of crosslinked gellan gum and non-crosslinked HEC layer (Figure 4B). HEC layer appeared more compact while gellan gum layer showed a lamellar structure as reported previously. ${ }^{17,56}$ In this study, the primary gellan gum layer did not show much difference from blank film. However, in the case of secondary HEC layer, the crosssection revealed a relatively loose lamellar structure with gapes. These micron size gaps could have formed due to evaporation of a minute quantity of volatile oil during drying and are in agreement with previously reported studies. ${ }^{17,57}$ 


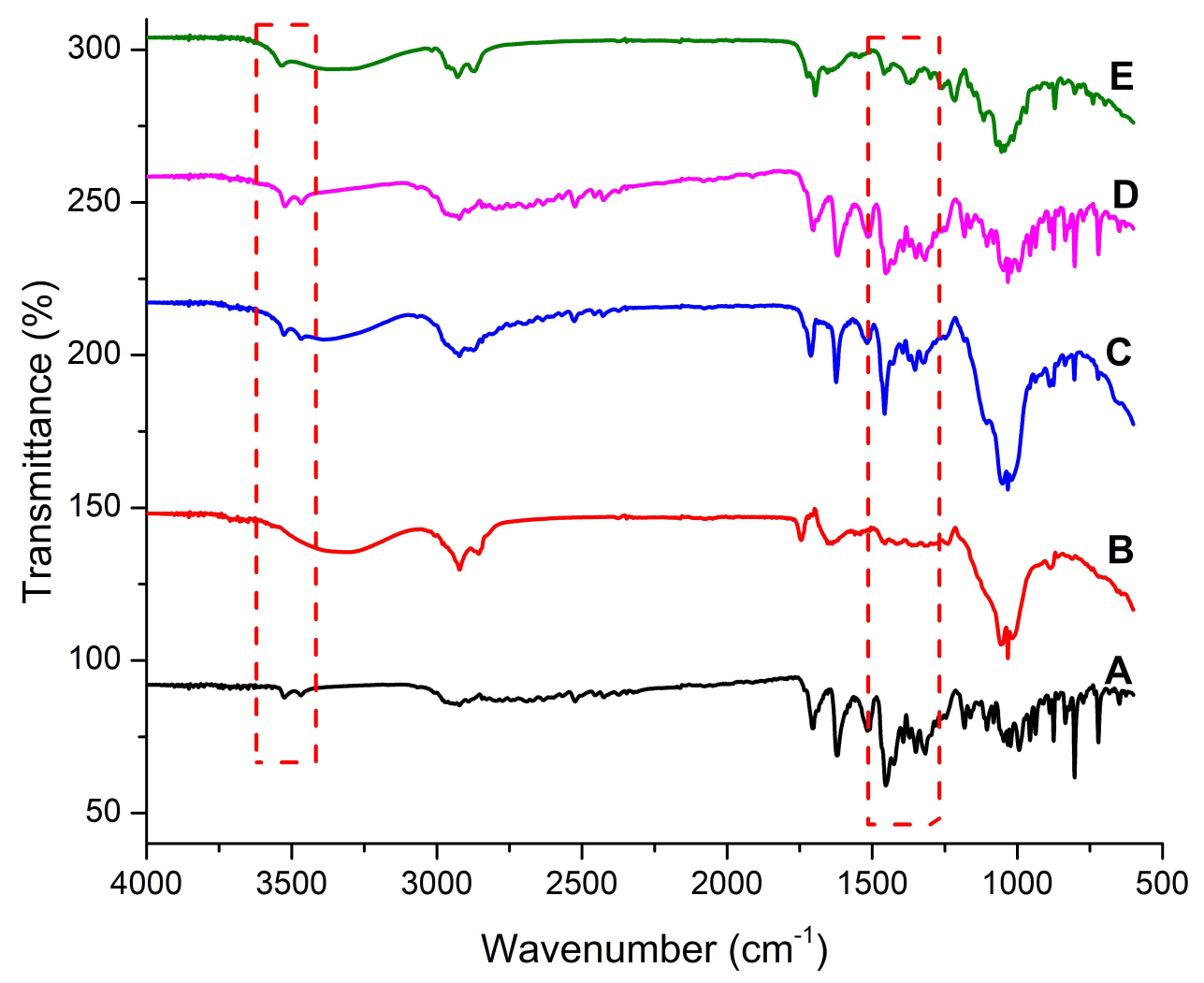

Figure 3 Fourier transform infrared spectroscopy (FTIR) spectra of (A) Mox, (B) blank film, (C) GG3, (D) O3, and (E) DI.
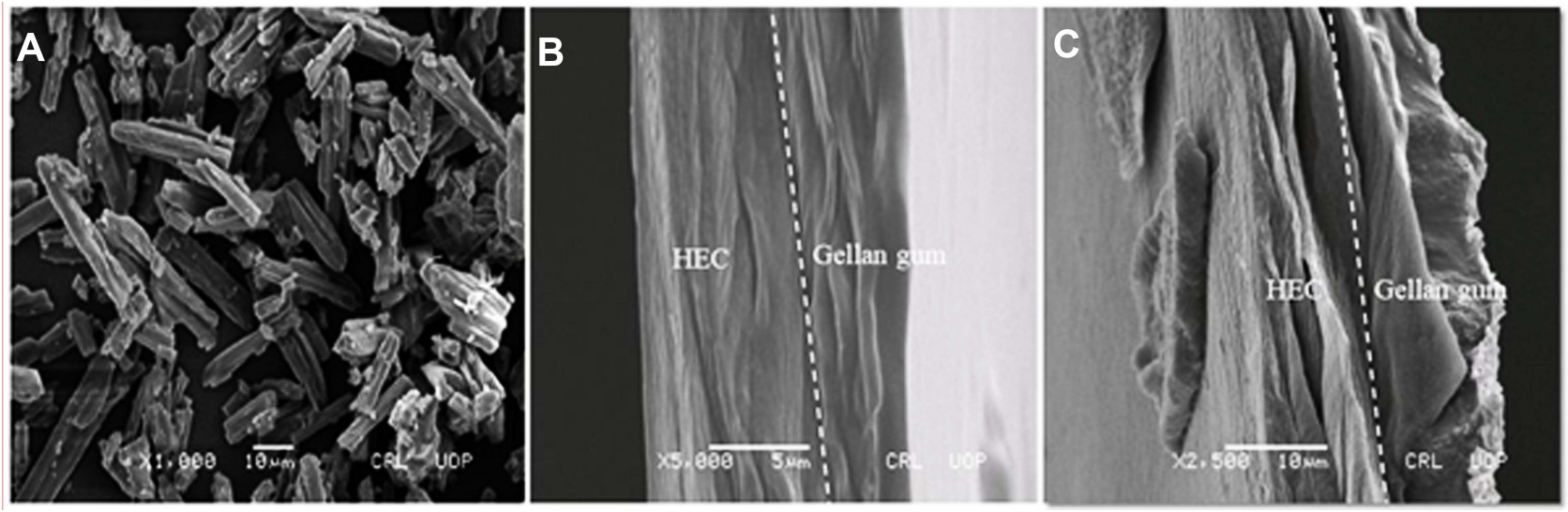

Figure 4 SEM micrographs of (A) Mox, (B) cross- sectional view of blank, and (C) GG3 film.

\section{Thermogravimetric Analysis}

The thermogravimetric test evaluated thermal stability of the film formulation indicated by weight loss with respect to change in temperature. The TGA graph of Mox, blank film, and GG3 formulation is presented in Figure 5. Mox exhibits no loss in weight until heated beyond $225^{\circ} \mathrm{C}$ due to thermal decomposition, ${ }^{58}$ thus confirming anhydrous Mox (Form I). ${ }^{59}$ The blank and GG3 formulation TGA graphs represented an initial weight loss from $40^{\circ} \mathrm{C}-80^{\circ} \mathrm{C}$ probably due to moisture loss from the films. Then a secondary weight loss event occurred at about $225^{\circ} \mathrm{C}$, which was attributed to the thermal decomposition of Moxifloxacin. However, the weight loss was significantly higher for films which might be due to thermal decomposition of other excipients present in the film formulations. From the TGA results, it can be concluded that the prepared films were stable up to $225^{\circ} \mathrm{C}$, which is well above the normal storage temperature for pharmaceutical products. 


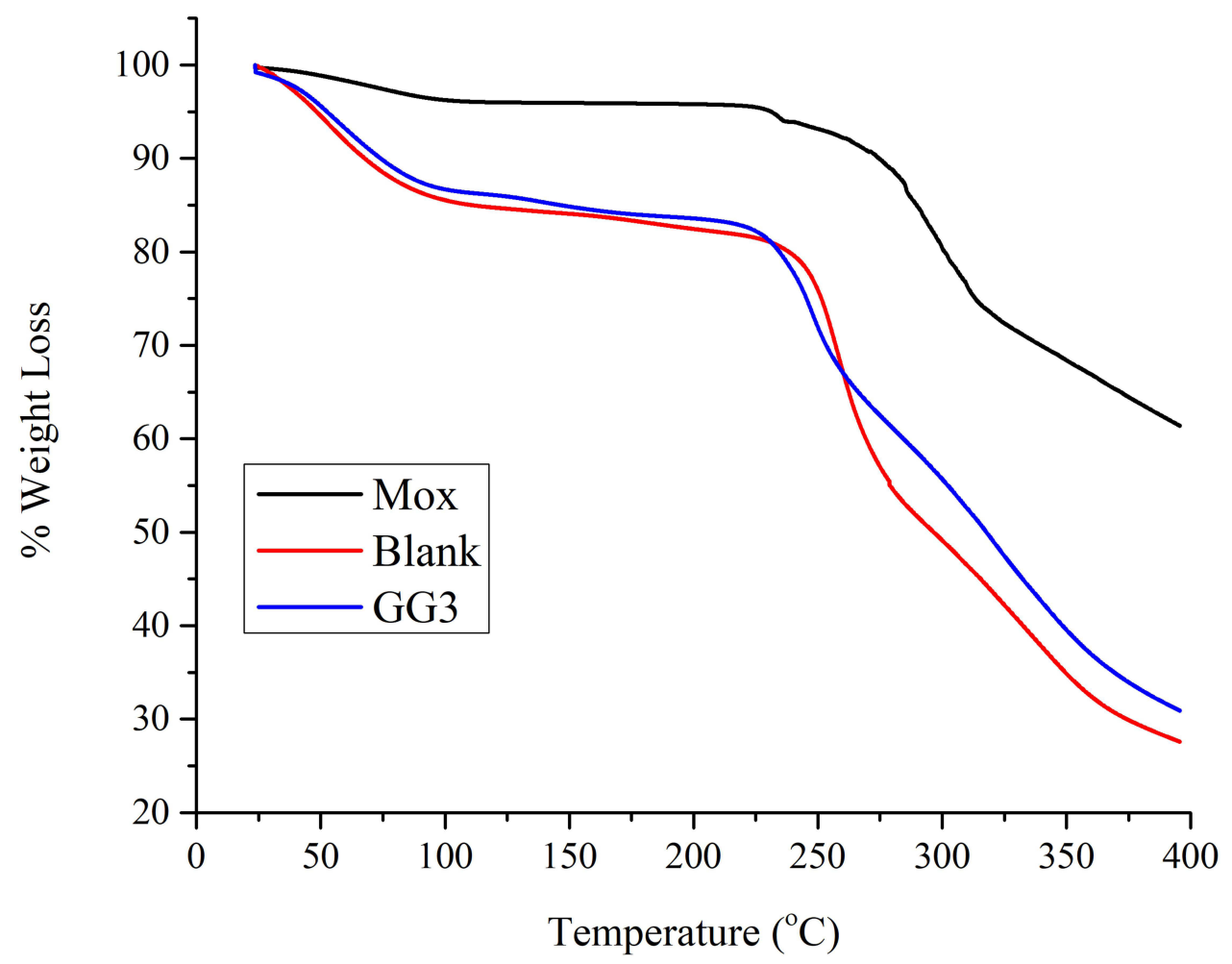

Figure 5 TGA graph of Mox, blank film, and GG3.

\section{Differential Scanning Calorimetry (DSC)}

The DSC thermogram of Mox, blank, and GG3 formulation are presented in Figure 6. The pure drug thermogram exhibited an endothermic peak at approximately $237^{\circ} \mathrm{C} .{ }^{60}$ The GG3 formulation shown did not show any endothermic melting peak of Mox, thus indicating the drug was either transformed into amorphous form in the formulation or it may have entangled within the polymeric crosslinks of film formulation. The transformation of crystalline Mox into amorphous form was further confirmed by the X-ray diffraction studies. The peaks appearing between $240-270^{\circ} \mathrm{C}$ in blank and GG3 film corresponds to polymer degradation due to thermal decomposition. Our results were in close agreement with the previously published study where gellan gum-based buccal films showed similar thermal decomposition of polymer. ${ }^{61}$

\section{X-Ray Diffractometry (XRD)}

$\mathrm{XRD}$ is a powerful and non-destructive technique to reveal the crystallinity or amorphicity of materials. The X-ray diffractogram of Mox, blank, and the optimized film is illustrated in Figure 7.

The diffractogram of Mox presented intense reflections at Bragg's angle $(2 \theta)$ of $8.3^{\circ}, 10.1^{\circ}, 14.6^{\circ}, 17.3^{\circ}$, and $27^{\circ}$ (Figure 7A), which reflects the crystalline nature of the drug. ${ }^{49,62}$ However, no characteristic peaks of Mox were observed in GG3 (Figure 7C), which indicates the dispersion of drug in the amorphous state. XRD results were in complete agreement with the DSC results and were further supported by previously reported studies. ${ }^{62,63}$ Amorphous state of drug plays an important role in enhancing the dissolution rate and bioavailability due to higher solubility as compared to its crystalline form. The amorphous form is a metastable state and drug generally transforms into crystalline forms with aging, which may compromise the stability of products. However, amorphous drug entanglement within bulky polymeric chains slows down the conversion of amorphous form into crystalline form. ${ }^{64}$

\section{Mucoadhesive Test}

Diseases of the oral cavity such as periodontitis, cancer, ulcers, dental carriers, and mucositis pose a major health burden across the globe. In these conditions, localized treatment strategies have proven effective. Thus, mucoadhesive dosage forms have gained substantial attention recently. In mucoadhesive films, hydrophilic polymers are mostly employed, which swell, and polymeric chains interact with mucin molecules in buccal mucosa to accomplish mucoadhesion. ${ }^{45,65}$ The mucoadhesive strength of 


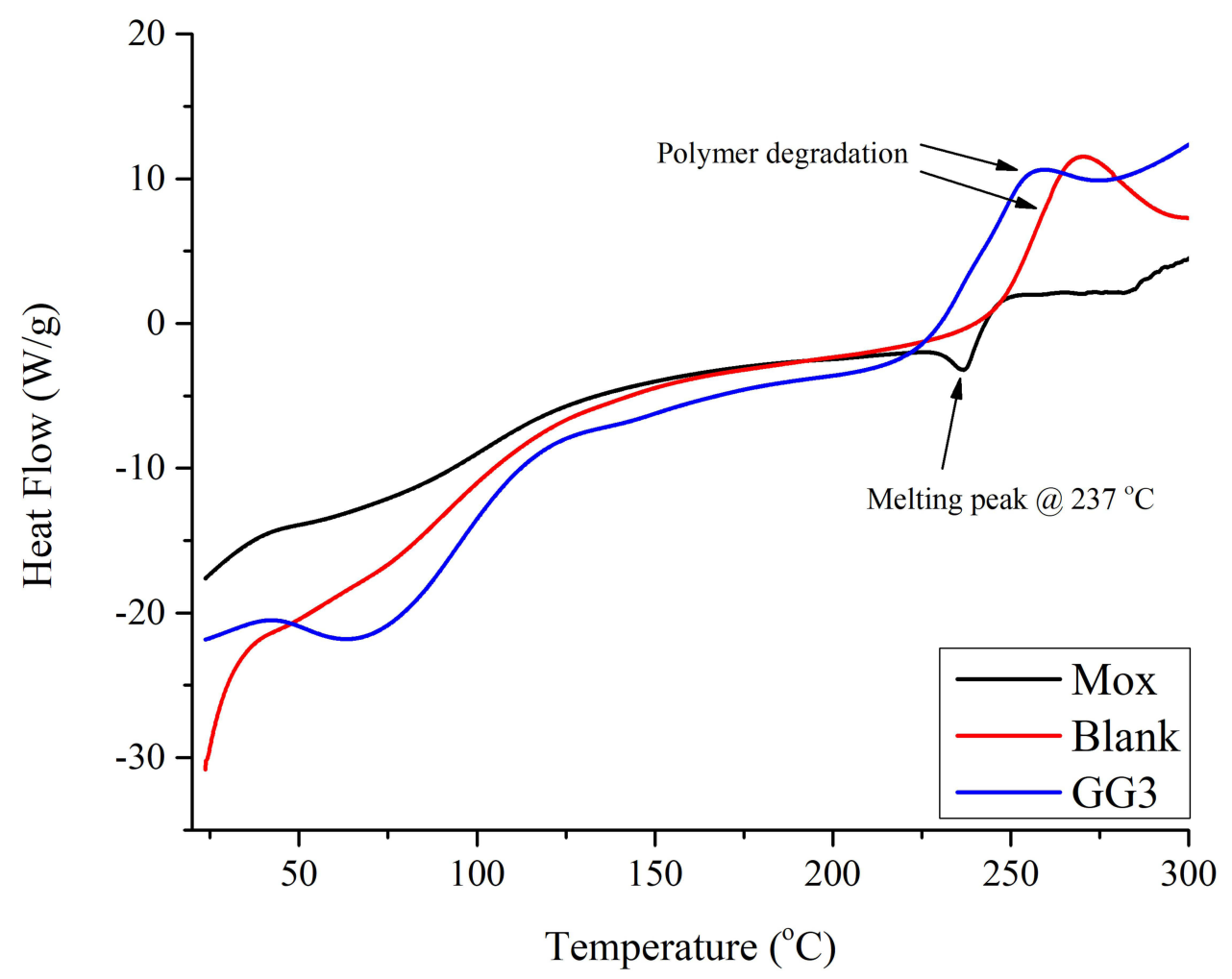

Figure 6 DSC thermogram of Mox, blank film, and GG3.

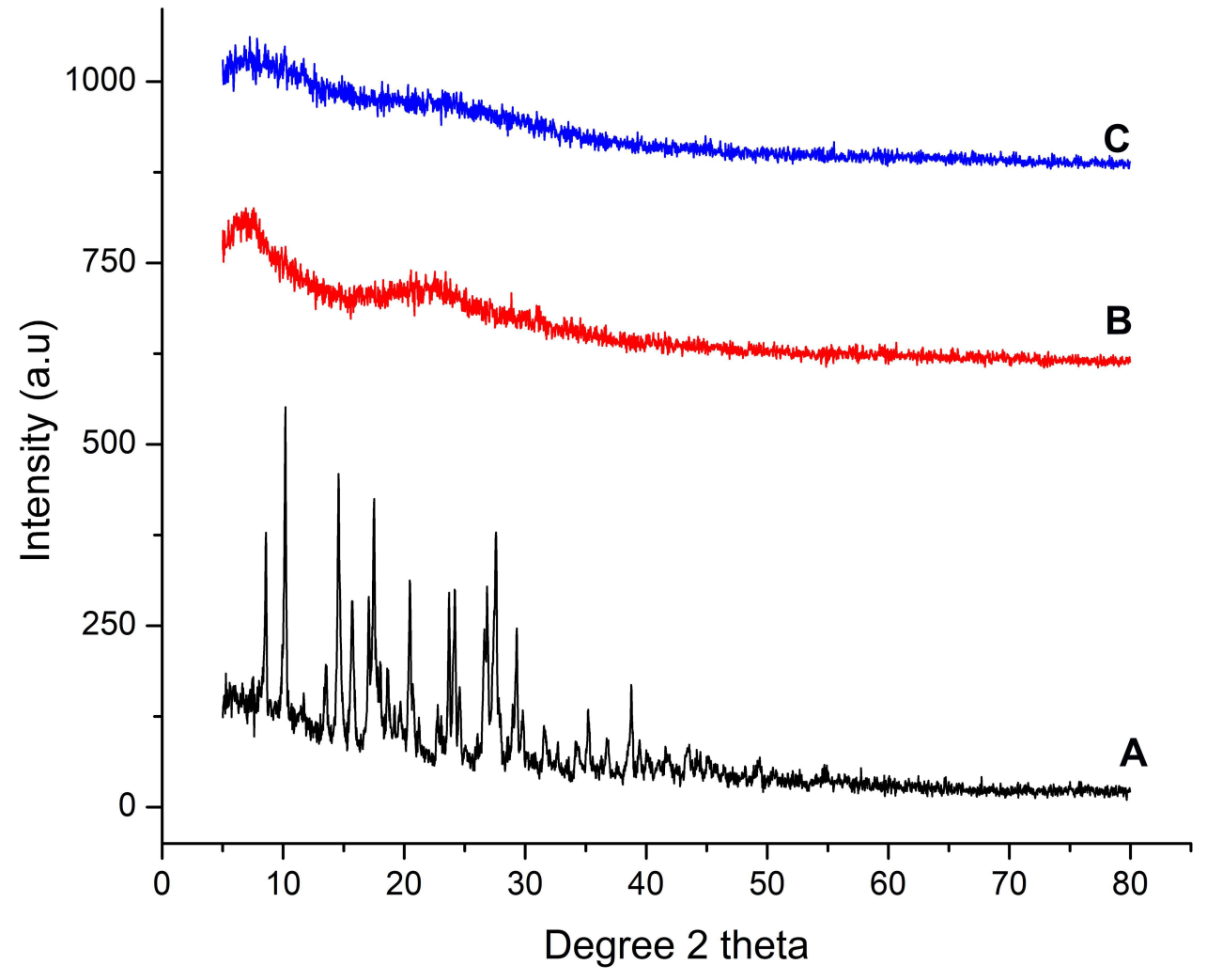

Figure 7 X-ray diffractogram of (A) Mox, (B) blank film, and (C) GG3. 
Table 4 Force of Adhesion and Bond Strength of the Selected Formulation

\begin{tabular}{|l|l|l|}
\hline Formulation & $\begin{array}{l}\text { Force of Adhesion } \\
\mathbf{( N )} \pm \mathbf{S D}\end{array}$ & $\begin{array}{l}\text { Bond Strength } \\
\mathbf{( N / \mathbf { c m } ^ { 2 }} \mathbf{\text { }} \mathbf{\pm S D}\end{array}$ \\
\hline Blank & $1.17 \pm 0.05$ & $0.53 \pm 0.01$ \\
GG3 & $0.91 \pm 0.02$ & $0.40 \pm 0.01$ \\
\hline
\end{tabular}

films is usually measured from its force of adhesion with the oral mucosa and the bond strength. For the prepared films, the values for mucoadhesive strength of blank and optimized films are summarized in Table 4.

In comparison, blank film demonstrated slightly higher force of adhesion than optimized formulations (GG3). This is linked with the swelling index of respective films, as discussed in the Swelling Studies section. In the literature, it is reported that mucoadhesive strength of the film is directly proportional to the swelling index of films. ${ }^{66}$ Moreover, hydrophilic groups in gellan gum such as hydroxyl and carboxylic groups bind with the mucin through hydrogen bonding to facilitate mucoadhesion. ${ }^{61}$ This prolongs the retention of films in the oral cavity by resisting the wash off effect of saliva and mastication forces for controlled release of actives.

\section{In vitro Drug Release Study}

The prepared bilayer mucoadhesive films showed a high entrapment efficiency which ranged from $95-98 \%$. Thus, the films were subjected to drug release studies. The optimized formulations (GG3) and D1 were evaluated for drug release efficiency for 48 hours. Both films demonstrated a biphasic release profile with initial burst release followed by sustained release of Mox over a 48-hour study period, as shown in Figure 8.

The drug loaded film (D1) released $28 \%$ of drug during the first 3 hours followed by cumulative drug release of $82 \%$ up to 48 hours. In the case of GG3, only $19 \%$ of drug was released during the first 3 hours. This was attributed to the presence of clove oil in the immediate layer, which reduces the porosity of the films and behaves as an additional barrier to prevent the penetration of dissolution media. This is in agreement with previously reported studies about bilayer films, where contents of the secondary layer affected the release of actives from the primary layer. ${ }^{67,68}$

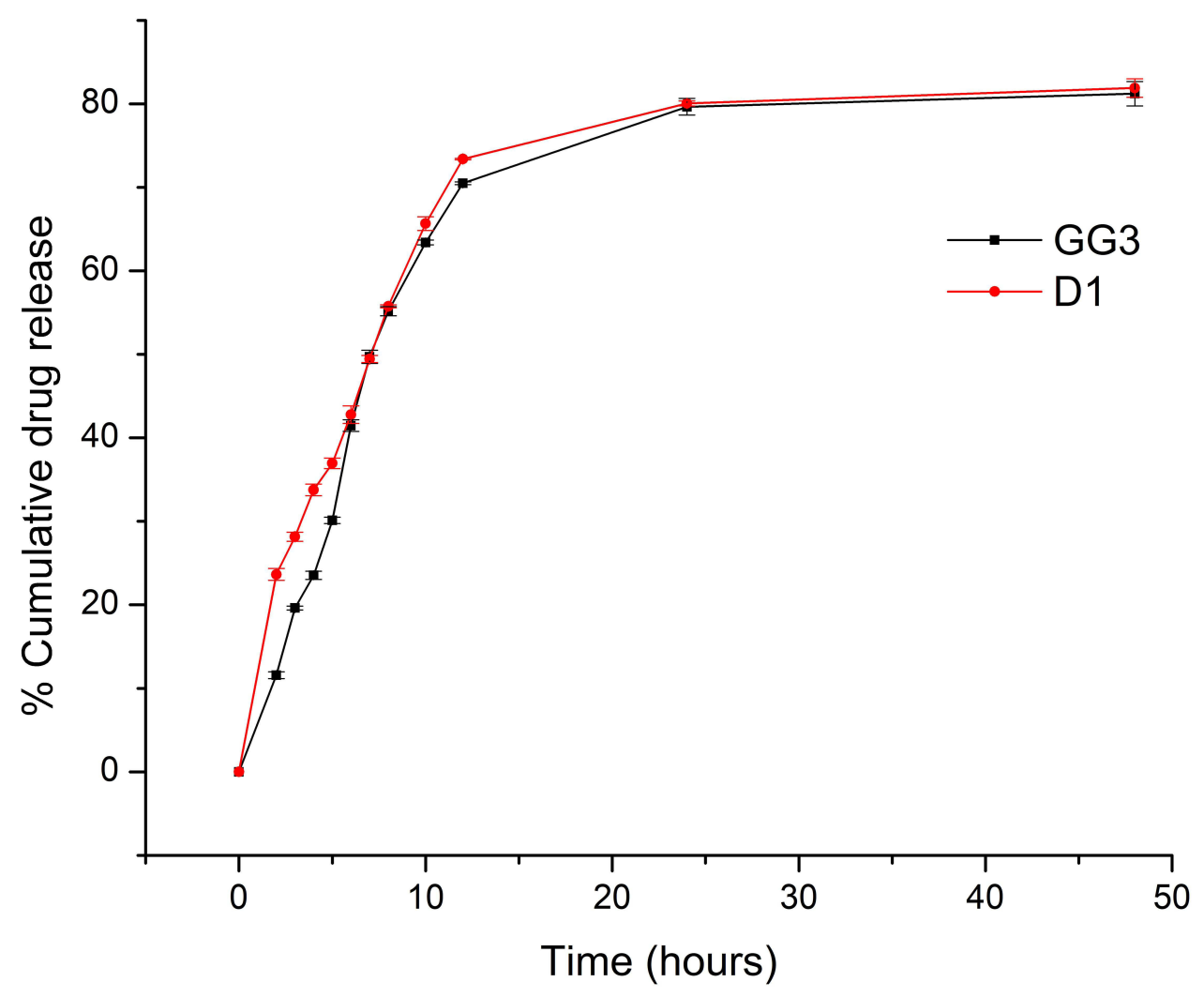

Figure 8 Cumulative percent release of Mox from GG3 and DI bilayer films at different time intervals. Error bars represent standard deviation of three replicates. 
Considering the end application of the bilayer film for periodontitis, this effect was desirable. Initial antibacterial cover and pain relief will be provided by clove oil released from the secondary (immediate) layer. Sustained release of Mox from the primary layer provides controlled release of active at the target site for continuous antibacterial cover. Nevertheless, the slow release of Mox from the controlled layer could possibly offer multiple benefits including avoidance of the subtherapeutic level of drug, prolonged antibacterial cover, and less side-effects of Mox.

Drug release data were subsequently fitted to various kinetic models to further investigate the drug release mechanism from mucoadhesive bilayer buccal films. Zeroorder, first-order, Higuchi, and Korsmeyer-Peppas models were investigated and the best-fit model was chosen based on respective correlation coefficient $\left(r^{2}\right)$ values, as presented in Table 5 .

For the films containing only drug, the drug release predominantly involved first-order release kinetics with the release mechanism following the Korsmeyer-Peppas model. According to the Korsmeyer-Peppas model, the Mox release followed non-Fickian diffusion, as can be explained by the release exponent (n) value. On the contrary, the drug release from GG3 formulation involved zero-order kinetics. This was further confirmed by the Korsmeyer-Peppas model release exponent (n) value, which suggested non-Fickian diffusion (case II) of drug owing to swelling or polymeric chain relaxation in the film matrix. Thus, the GG3 formulation resulted in mucoadhesive films with a precise control over drug release in a controlled manner.

\section{Permeation Studies}

Finally, Franz diffusion cells were employed for studying the drug permeation across a skin mimic, namely cellulose acetate membrane. Various permeation kinetic parameters such as $J_{s s,} K p$, and lag time were calculated from the cumulative amount permeated versus time plot. The permeation data, summarized in Table 6, suggested slightly higher and faster diffusion of drug from film formulation containing drug alone (D1) as compared to GG3 formulation. The corresponding lag time of 0.029 hour is indicative of the immediate onset of diffusion across cellulose acetate membrane in the case for D1. On the contrary, the lag time for GG3 formulation was higher than that for the D1 formulation, which was attributed to the presence of oil in the film formulation. Oils presented more hydrophobic environment and thus penetration of aqueous media in the film formulation was restricted, thereby slowing down the hydration of film. This could have further contributed to a slower diffusion of drug from the membrane, as depicted by a relatively low permeability coefficient and steady-state flux values. The presence of essential oil in the membrane might have created an additional layer for the Mox to diffuse into receptor medium, as depicted by the lower $K p$ and $J_{s s}$ values for the GG3 formulation.

Overall, permeation studies confirmed slower yet more controlled drug release from the GG3 bilayer film formulation which is a prerequisite for mucoadhesive films used to treat clinical conditions such as periodontitis.

\section{Conclusion}

Mucoadhesive bilayer buccal films were formulated for the dual delivery of Mox and clove oil for possible

Table 5 Correlation Coefficient Values for Zero Order, First Order, and Higuchi, Korsmeyer-Peppas Model

\begin{tabular}{|l|c|c|c|c|c|}
\hline \multirow{2}{*}{ Formulation } & \multicolumn{3}{|c|}{ Release Kinetic Models } \\
\cline { 2 - 6 } & Zero-Order $\left.\mathbf{( R}^{2}\right)$ & First-Order $\left(\mathbf{R}^{2}\right)$ & Higuchi Model $\left.\mathbf{( R}^{2}\right)$ & \multicolumn{2}{|c|}{ Korsmeyer-Peppas Model } \\
\cline { 3 - 6 } & & & & $\left.\mathbf{( R}^{\mathbf{2}}\right)$ & $\mathbf{n}$ \\
\hline D & 0.9460 & 0.9834 & 0.9444 & 0.9895 & 0.72 \\
GG3 & 0.9901 & 0.9663 & 0.8453 & 0.9903 & 1.02 \\
\hline
\end{tabular}

Table 6 Permeation Parameters of Mox from Bilayer Film Formulation

\begin{tabular}{|l|c|c|c|c|}
\hline Formulation & Cumulative Drug Permeation $\left(\mu \mathrm{g} / \mathrm{cm}^{2}\right)$ & Lag Time $(\mathbf{h})$ & $K \mathbf{p} \times 1 \mathbf{0}^{-3}\left(\mathrm{cmh}^{-1}\right)$ & $\mathrm{Jss}\left(\mu \mathrm{g} / \mathrm{cm}^{2} / \mathbf{h}\right)$ \\
\hline D & $658 \pm 3.5$ & $0.029 \pm 0.007$ & $2.80 \pm 0.09$ & $29.44 \pm 3.03$ \\
GG3 & $639 \pm 6.1$ & $0.092 \pm 0.005$ & $2.19 \pm 0.20$ & $23.06 \pm 2.94$ \\
\hline
\end{tabular}


treatment of periodontitis. After initial screening, GG3 was selected as an optimized bilayer film based on physical characteristics and maximum antibacterial activity against S. aureus and E. coli. The immediate layer dissolved quickly to release clove oil, but the sustained layer swelled slowly to release Mox in a controlled manner. SEM analysis confirmed the successful development of bilayer film, while FTIR showed compatibility between actives and the formulation ingredients. XRD and DSC revealed the dispersion of Mox at the molecular level. The mucoadhesive strength of the optimized film was enough to hold it in the oral cavity for a prolonged time with controlled release of Mox over 48 hours. Thus, the prepared mucoadhesive bilayer film containing Mox and clove oil could possibly offer synergistic activity against pathogens involved in periodontitis and provide instant pain relief. In the future, this study can be extended to investigate this particular formulation in in-vivo settings involving animals and human volunteers to confirm its clinical application.

\section{Acknowledgment}

The authors would like to thanks GCUF for providing laboratory access and chemicals to perform this research. We would also like to thanks Dr. Muhammad Ihtisham Umar for helping with the artwork.

\section{Author Contributions}

All authors made a significant contribution to the work reported, whether that is in the conception, study design, execution, acquisition of data, analysis, and interpretation, or in all these areas; took part in drafting, revising or critically reviewing the article; gave final approval of the version to be published; have agreed on the journal to which the article has been submitted; and agree to be accountable for all aspects of the work.

\section{Disclosure}

The authors report no conflicts of interest in this work.

\section{References}

1. Preshaw P, Alba A, Herrera D, et al. Periodontitis and diabetes: a two-way relationship. Diabetologia. 2012;55(1):21-31. doi:10.1007/ s00125-011-2342-y

2. Chen X, Wu G, Feng Z, et al. Advanced biomaterials and their potential applications in the treatment of periodontal disease. Crit Rev Biotechnol. 2016;36(4):760-775. doi:10.3109/07388551.2015. 1035693
3. Baranov N, Popa M, Atanase LI, Ichim DL. Polysaccharide-based drug delivery systems for the treatment of periodontitis. Molecules. 2021;26(9):2735. doi:10.3390/molecules26092735

4. Tominari T, Sanada A, Ichimaru R, et al. Gram-positive bacteria cell wall-derived lipoteichoic acid induces inflammatory alveolar bone loss through prostaglandin E production in osteoblasts. Sci Rep. 2021;11(1):1-12. doi:10.1038/s41598-021-92744-5

5. Herrera D, Matesanz P, Bascones-Martínez A, Sanz M. Local and systemic antimicrobial therapy in periodontics. J Evid Based Dent Pract. 2012;12(3):50-60. doi:10.1016/S1532-3382(12)70013-1

6. Ahmed MG, Harish N, Charyulu RN, Prabhu P. Formulation of chitosan-based ciprofloxacin and diclofenac film for periodontitis therapy. Trop J Pharm Res. 2009;8(1):33-41. doi:10.4314/tjpr.v8i1.14710

7. Greenstein G, Polson A. The role of local drug delivery in the management of periodontal diseases: a comprehensive review. J Periodontol. 1998;69(5):507-520. doi:10.1902/jop.1998.69.5.507

8. Khan G, Yadav SK, Patel RR, Nath G, Bansal M, Mishra B. Development and evaluation of biodegradable chitosan films of metronidazole and levofloxacin for the management of periodontitis. Aaps Pharmscitech. 2016;17(6):1312-1325. doi:10.12 08/s12249-015-0466-y

9. Zaman M, Hanif M, Shaheryar ZA. Development of tizanidine HCL-meloxicam loaded mucoadhesive buccal films: in-vitro and in-vivo evaluation. PLoS One. 2018;13(3):e0194410. doi:10.1371/ journal.pone. 0194410

10. Thu H-E, Zulfakar MH, Ng S-F. Alginate based bilayer hydrocolloid films as potential slow-release modern wound dressing. Int $J$ Pharm. 2012;434(1-2):375-383. doi:10.1016/j.ijpharm.2012.05.044

11. Steven J, Fountain W, Cui Z, Mumper RJ. Transmucosal delivery of testosterone in rabbits using novel bi-layer mucoadhesive wax-film composite disks. J Pharm Sci. 2002;91(9):2016-2025. doi:10.1002/jps.10198

12. Kumar R. Fast dissolving films: a unique strategy for drug delivery. Asian J Pharm Res. 2014;4(1):47-55.

13. Lim SY, Dafydd M, Ong J, et al. Mucoadhesive thin films for the simultaneous delivery of microbicide and anti-inflammatory drugs in the treatment of periodontal diseases. Int J Pharm. 2020;573:118860. doi:10.1016/j.ijpharm.2019.118860

14. Ashri LY, Amal El Sayeh F, Ibrahim MA, Alshora DH. Optimization and evaluation of chitosan buccal films containing tenoxicam for treating chronic periodontitis: in vitro and in vivo studies. J Drug Deliv Sci Technol. 2020;57:101720. doi:10.1016/j.jddst.2020.101720

15. Paczkowska-Walendowska M, Dvořák $J$, Rosiak N, et al. Buccal resveratrol delivery system as a potential new concept for the periodontitis treatment. Pharmaceutics. 2021;13(3):417. doi:10.3390/ pharmaceutics 13030417

16. Kang KS, Veeder GT, Mirrasoul PJ, Kaneko T, Cottrell IW. Agar-like polysaccharide produced by a pseudomonas species: production and basic properties. Appl Environ Microbiol. 1982;43(5):1086-1091. doi:10.1128/aem.43.5.1086-1091.1982

17. Mahmood H, Khan IU, Asif M, et al. In vitro and in vivo evaluation of gellan gum hydrogel films: assessing the co impact of therapeutic oils and ofloxacin on wound healing. Int J Biol Macromol. 2020;166:483-495. doi:10.1016/j.ijbiomac.2020.10.206

18. Rowe, Raymond C., Paul J. Sheskey, and Marian E. Quinn. Handbook of pharmaceutical excipients. London: Pharmaceutical Press; 2009.

19. Bambeke V. Quinolones in 2005: an update. Clin Microbiol Infect. 2005;11(4):256-280.

20. Dholakia M, Thakkar V, Patel N, Gandhi T. Development and characterisation of thermo reversible mucoadhesive moxifloxacin hydrochloride in situ ophthalmic gel. J Pharm Bioallied Sci. 2012;4(Supp1 1):S42. doi:10.4103/0975-7406.94138

21. Pinto E, Vale-Silva L, Cavaleiro C, Salgueiro L. Antifungal activity of the clove essential oil from Syzygium aromaticum on Candida, Aspergillus and dermatophyte species. J Med Microbiol. 2009;58 (11):1454-1462. doi:10.1099/jmm.0.010538-0 
22. Arafa MG, Ghalwash D, El-Kersh DM, Elmazar M. Propolis-based niosomes as oromuco-adhesive films: a randomized clinical trial of a therapeutic drug delivery platform for the treatment of oral recurrent aphthous ulcers. Sci Rep. 2018;8(1):1-14. doi:10.1038/s41598018-37157-7

23. Manconi M, Petretto G, D'hallewin G, et al. Thymus essential oil extraction, characterization and incorporation in phospholipid vesicles for the antioxidant/antibacterial treatment of oral cavity diseases. Colloids Surf B Biointerfaces. 2018;171:115-122. doi:10.1016/j. colsurfb.2018.07.021

24. São Pedro A, Cabral-Albuquerque E, Ferreira D, Sarmento B. Chitosan: an option for development of essential oil delivery systems for oral cavity care? Carbohydr Polym. 2009;76(4):501-508. doi:10.1016/j.carbpol.2008.12.016

25. Balouiri M, Sadiki M, Ibnsouda SK. Methods for in vitro evaluating antimicrobial activity: a review. J Pharm Anal. 2016;6(2):71-79. doi:10.1016/j.jpha.2015.11.005

26. Shahzad Y, Maqbool M, Hussain T, et al. Natural and semisynthetic polymers blended orodispersible films of citalopram. Nat Prod Res. 2020;34(1):16-25. doi:10.1080/14786419.2018.1552698

27. Irfan M, Rabel S, Bukhtar Q, Qadir MI, Jabeen F, Khan A. Orally disintegrating films: a modern expansion in drug delivery system. Saudi Pharm J. 2016;24(5):537-546. doi:10.1016/j.jsps.2015.02.024

28. Abu-Huwaij R, Obaidat RM, Sweidan K, Al-Hiari Y. Formulation and in vitro evaluation of xanthan gum or carbopol 934-based mucoadhesive patches, loaded with nicotine. Aaps Pharmscitech. 2011;12(1):21-27. doi:10.1208/s12249-010-9534-5

29. Prezotti FG, Cury BSF, Evangelista RC. Mucoadhesive beads of gellan gum/pectin intended to controlled delivery of drugs. Carbohydr Polym. 2014;113:286-295. doi:10.1016/j.carbpol.2014. 07.021

30. Eroğlu H, Sargon MF, Öner L. Chitosan formulations for steroid delivery: effect of formulation variables on in vitro characteristics. Drug Dev Ind Pharm. 2007;33(3):265-271. doi:10.1080/0363904 0600713134

31. Colley H, Said Z, Santocildes-Romero M, et al. Pre-clinical evaluation of novel mucoadhesive bilayer patches for local delivery of clobetasol-17-propionate to the oral mucosa. Biomaterials. 2018;178:134-146. doi:10.1016/j.biomaterials.2018.06.009

32. Pendekal MS, Tegginamat PK. Formulation and evaluation of a bioadhesive patch for buccal delivery of tizanidine. Acta Pharm Sinica B. 2012;2(3):318-324. doi:10.1016/j.apsb.2011.12.012

33. Mukherjee D, Bharath S. Design and characterization of double layered mucoadhesive system containing bisphosphonate derivative. ISRN Pharm. 2013;2013. doi:10.1155/2013/604690

34. Suvakanta D. Kinetic modeling on drug release from controlled drug delivery systems. Acta Pol Pharm. 2010;67(3):217-223.

35. Carstensen JT. Modeling and Data Treatment in the Pharmaceutical Sciences. CRC Press; 1996.

36. Bourne D, Banker G, Rhodes C. Modern Pharmaceutics. New York: Informa Healthcare; 2002:67-92.

37. Dressman J, Fleisher D, Amidon G. Physicochemical model for dose-dependent drug absorption. $J$ Pharm Sci. 1984;73 (9):1274-1279. doi:10.1002/jps.2600730922

38. Nastiti CMRR, Ponto T, Mohammed Y, Roberts MS, Benson HAE. Novel nanocarriers for targeted topical skin delivery of the antioxidant resveratrol. Pharmaceutics. 2020;12(2):108. doi:10.3390/ pharmaceutics 12020108

39. Jirovetz L, Buchbauer G, Stoilova I, Stoyanova A, Krastanov A, Schmidt E. Chemical composition and antioxidant properties of clove leaf essential oil. J Agric Food Chem. 2006;54(17):63 03-6307. doi:10.1021/jf060608c

40. Oulkheir S, Aghrouch M, El Mourabit F, et al. Antibacterial activity of essential oils extracts from cinnamon, thyme, clove and geranium against a gram negative and gram positive pathogenic bacteria. J Dis Med Plants. 2017;3(2):1.
41. Schedletzky H, Wiedemann B, Heisig P. The effect of moxifloxacin on its target topoisomerases from Escherichia coli and Staphylococcus aureus. J Antimicrobial Chemother. 1999;43 (suppl_2):31-37. doi:10.1093/jac/43.suppl_2.31

42. Mirzaeei S, Mansurian M, Asare-Addo K, Nokhodchi A. Metronidazole-and amoxicillin-loaded PLGA and PCL nanofibers as potential drug delivery systems for the treatment of periodontitis: in vitro and in vivo evaluations. Biomedicines. 2021;9(8):975. doi:10.3390/biomedicines9080975

43. Nair AB, Kumria R, Harsha S, Attimarad M, Al-Dhubiab BE, Alhaider IA. In vitro techniques to evaluate buccal films. J Control Release. 2013;166(1):10-21. doi:10.1016/j.jconrel.2012.11.019

44. Karki S, Kim H, Na S-J, Shin D, Jo K, Lee J. Thin films as an emerging platform for drug delivery. Asian J Pharm Sci. 2016;11 (5):559-574. doi:10.1016/j.ajps.2016.05.004

45. Boateng J, Popescu A. Composite bi-layered erodible films for potential ocular drug delivery. Colloids Surf $B$ Biointerfaces. 2016;145:353-361. doi:10.1016/j.colsurfb.2016.05.014

46. Malana MA, Zafar ZI, Zuhra R. Effect of cross linker concentration on swelling kinetics of a synthesized ternary co-polymer system. J Chem Soc Pak. 2012;34(4):793.

47. Hameed M, Rasul A, Waqas MK, et al. Formulation and evaluation of a clove oil-encapsulated nanofiber formulation for effective wound-healing. Molecules. 2021;26(9):2491. doi:10.3390/molecules 26092491

48. Pawar PK, Katara R, Majumdar DK. Design and evaluation of moxifloxacin hydrochloride ocular insert. Acta Pharm. 2012;62 (1):93-104. doi:10.2478/v10007-012-0002-5

49. Pawar M. Preparation and in vitro/ex vivo evaluation of moxifloxacin-loaded PLGA nanosuspensions for ophthalmic application. Sci Pharm. 2013;81(2):591-606. doi:10.3797/scipharm.1204-16

50. Fu R, Li C, Yu C, et al. A novel electrospun membrane based on moxifloxacin hydrochloride/poly (vinyl alcohol)/sodium alginate for antibacterial wound dressings in practical application. Drug Deliv. 2016;23(3):818-829. doi:10.3109/10717544.2014.918676

51. Deyab M. Hydroxyethyl cellulose as efficient organic inhibitor of zinc-carbon battery corrosion in ammonium chloride solution: electrochemical and surface morphology studies. J Power Sources. 2015;280:190-194. doi:10.1016/j.jpowsour.2015.01.107

52. Silva-Correia J, Oliveira JM, Caridade S, et al. Gellan gum-based hydrogels for intervertebral disc tissue-engineering applications. J Tissue Eng Regen Med. 2011;5(6):e97-e107. doi:10.1002/term.363

53. Lee M-W, Tsai H-F, Wen S-M, Huang C-H. Photocrosslinkable gellan gum film as an anti-adhesion barrier. Carbohydr Polym. 2012;90(2):1132-1138. doi:10.1016/j.carbpol.2012.06.064

54. Mohammed MJ, Al-Bayati FA. Isolation and identification of antibacterial compounds from Thymus kotschyanus aerial parts and Dianthus caryophyllus flower buds. Phytomedicine. 2009;16(67):632-637. doi:10.1016/j.phymed.2008.12.026

55. Patel U, Chotai N, Nagda C. Design and evaluation of polymeric ocular drug delivery system for controlled delivery of moxifloxacin hydrochloride: in vitro and in vivo evaluation. Acta Pharm Sci. 2010;52(4):523-535.

56. Bellini MZ, Oliva-Neto P, Moraes ÂM. Properties of films obtained from biopolymers of different origins for skin lesions therapy. Braz Arch Biol Tech. 2015;58(2):289-299. doi:10.1590/S1516-8913201500305

57. Chaiwarit T, Ruksiriwanich W, Jantanasakulwong K, Jantrawut P. Use of orange oil loaded pectin films as antibacterial material for food packaging. Polymers. 2018;10(10):1144. doi:10.3390/polym 10101144

58. Eedara BB, Rangnekar B, Doyle C, Cavallaro A, Das SC. The influence of surface active 1-leucine and 1, 2-dipalmitoyl-sn-glycero -3-phosphatidylcholine (DPPC) in the improvement of aerosolization of pyrazinamide and moxifloxacin co-spray dried powders. Int J Pharm. 2018;542(1-2):72-81. doi:10.1016/j.ijpharm.2018.03. 005 
59. Al Omari MMH, Jaafari DS, Al-Sou'od KA, Badwan AA. Chapter seven - moxifloxacin hydrochloride. In: Brittain HG, editor. Profiles of Drug Substances, Excipients and Related Methodology. Vol. 39. Academic Press; 2014:299-431.

60. Nayak N, Bharani S, Thakur R. Formulation and evaluation of $\mathrm{pH}$ triggered in situ ophthalmic gel of Moxifloxacin hydrochloride. Int J Pharm PharmSci. 2012;4(2):452-459.

61. Fernandes FP, Fortes AC, da Cruz Fonseca SG, Breitkreutz J, Ferraz HG. Manufacture and characterization of mucoadhesive buccal films based on pectin and gellan gum containing triamcinolone acetonide. Int J Polym Sci. 2018;2018. doi:10.1155/2018/2403802

62. Giram PS, Shitole A, Nande SS, Sharma N, Garnaik B. Fast dissolving moxifloxacin hydrochloride antibiotic drug from electrospun eudragit L-100 nonwoven nanofibrous mats. Mater Sci Eng C. 2018;92:526-539. doi:10.1016/j.msec.2018.06.031

63. Liu Q, Ouyang W-C, Zhou X-H, Jin T, Wu Z-W. Antibacterial activity and drug loading of moxifloxacin-loaded poly(vinyl alcohol)/chitosan electrospun nanofibers. Front Mater. 2021;8:36.

64. Tahir MA, Ali ME, Lamprecht A. Nanoparticle formulations as recrystallization inhibitors in transdermal patches. Int J Pharm. 2020;575:118886. doi:10.1016/j.ijpharm.2019.118886
65. Alves TF, Rios AC, da Silva Pontes K, et al. Bilayer mucoadhesive buccal film for mucosal ulcers treatment: development, characterization, and single study case. Pharmaceutics. 2020;12(7):657. doi:10. 3390/pharmaceutics12070657

66. Shiledar RR, Tagalpallewar AA, Kokare CR. Formulation and in vitro evaluation of xanthan gum-based bilayered mucoadhesive buccal patches of zolmitriptan. Carbohydr Polym. 2014;101: 1234-1242. doi:10.1016/j.carbpol.2013.10.072

67. Trevisol TC, Scartazzini L, Valério A, Guelli Ulson de Souza SMA, Bierhalz ACK, Valle JAB. Diclofenac release from alginate/carboxymethyl cellulose mono and bilayer films for wound dressing applications. Cellulose. 2020;27(11):6629-6642. doi:10.1007/s105 70-020-03217-3

68. Abruzzo A, Nicoletta FP, Dalena F, Cerchiara T, Luppi B, Bigucci F. Bilayered buccal films as child-appropriate dosage form for systemic administration of propranolol. Int J Pharm. 2017;531(1):257-265. doi:10.1016/j.ijpharm.2017.08.070

\section{Publish your work in this journal}

Drug Design, Development and Therapy is an international, peerreviewed open-access journal that spans the spectrum of drug design and development through to clinical applications. Clinical outcomes, patient safety, and programs for the development and effective, safe, and sustained use of medicines are a feature of the journal, which has also been accepted for indexing on PubMed Central. The manuscript management system is completely online and includes a very quick and fair peer-review system, which is all easy to use. Visit http://www. dovepress.com/testimonials.php to read real quotes from published authors. 